\title{
Adherence to Guidelines at a Stroke Prevention Clinic: A Follow-up Study
}

\author{
Bing Yu Chen, Heather Perkins, Eric Ehrensperger, Jeffrey Minuk, Lucy Vieira, \\ Theodore Wein, Robert Côté
}

\begin{abstract}
Background: In 2010, we published our stroke prevention clinic's performance as compared to Canadian stroke prevention guidelines. We now compare our clinic's adherence with guidelines to our previous results, following the implementation of an electronic documentation form. Methods: All new patients referred to our clinic (McGill University Health Center) for recent transient ischemic attack (TIA) or ischemic stroke between 2014 and 2017 were included. We compared adherence to guidelines to our previous report ( $N=408$ patients for period 2008-2010) regarding vascular risk management and treatment. Results: Three hundred and ninety-two patients were included, of which $36 \%$ had a TIA and 64\% had an ischemic stroke, with a mean age of 70 years and $43 \%$ female. Although the more recent cohort has shown a higher proportion of cardioembolic stroke compared to previous (19.1\% vs. 14.7\%) following new guidelines regarding prolonged cardiac monitoring, increased popularity in CT angiography has not translated into greater proportion of large-artery stroke subtype (26.3\% vs. $26.2 \%$ ). Blood pressure (BP) targets were achieved in $83 \%$ compared with $70 \%$ in our previous report $(p<0.01)$. Attainment of low-density lipoprotein cholesterol target was also improved in our recent study $(66 \%$ vs. $46 \%, p<0.01)$. No significant difference was found in the consistency of antithrombotic use (97.7\% vs. 99.8\%, $p=0.08)$. However, there was a decline in smoking cessation $(35 \%$ vs. $73 \%, p=0.02)$. Overall, optimal therapy status was better attained in the present cohort compared to the previous one $(52 \%$ vs. $22 \%, p<0.01)$. The male sex was associated with better attainment of optimal therapy status (odds ratio, $1.61 ; 95 \%$ confidence interval, 1.04-2.51). The number of follow-up visits and the length of follow-up were not associated with attainment of stroke prevention targets. Conclusions: Our study shows improvement in attainment of therapeutic goals as recommended by Canadian stroke prevention guidelines, possibly attributed in part to the implementation of electronic medical recording in our clinic. Areas for improvement include smoking cessation counseling and diabetes screening.
\end{abstract}

RÉSUMÉ: Mise en œuvre de lignes directrices dans une clinique de prévention des AVC: une étude de suivi. Contexte: En 2010, nous avons rendu publics les résultats de notre clinique de prévention des AVC en ce qui regarde les lignes directrices canadiennes de prévention des AVC. Suite à la mise en place d'un formulaire d'information électronique, nous voulons maintenant comparer l'adhésion actuelle de notre clinique à ces lignes directrices à celle mesurée en 2010. Méthodes: Tous les nouveaux patients adressés à notre clinique (Centre universitaire de santé McGill) pour des cas récents d'ischémie cérébrale transitoire (ICT) ou d'AVC ischémique survenus entre 2014 et 2017 ont été inclus dans cette étude. Nous avons ainsi comparé l'adhésion actuelle aux lignes directrices évoquées ci-haut à celle du précédent rapport $(\mathrm{N}=408$ patients pour la période allant de 2008 à 2010), et ce, en ce qui concerne la prise en charge du risque vasculaire et les traitements nécessaires. Résultats: Au total, 392 patients ont été inclus; de ce nombre, $36 \%$ d'entre eux avaient été victimes d'ICT tandis que $64 \%$ avaient été victimes d'un AVC ischémique. Leur âge moyen était de 70 ans et $43 \%$ d'entre eux étaient de sexe féminin. Bien que la cohorte la plus récente, à la suite de l'introduction de nouvelles lignes directrices portant sur la surveillance cardiaque prolongée, ait donné à voir une proportion plus élevée d'AVC d'origine cardio-embolique comparativement à la précédente (19,1 \% par opposition à 14,7 \%), la popularité croissante de l'angiographie par tomodensitométrie ne s'est pas traduite par une proportion plus grande de sous-types d'AVC affectant de grandes artères (26,3\% de 2014 à 2017 par opposition à 26,2 \% de 2008 à 2010). Les valeurs cibles fixées en matière de pression artérielle ont été atteintes dans $83 \%$ des cas comparativement à $70 \%$ des cas dans notre rapport précédent ( $\mathrm{p}<0,01$ ). L'atteinte de la valeur cible en ce qui concerne le taux de LDL-cholestérol (lipoprotéines de faible intensité) a également été améliorée dans notre plus récent rapport (66\% par opposition à $46 \% ; \mathrm{p}<0,01)$. Ajoutons aussi qu'aucune différence notable n'a été observée quant à une utilisation constante d'anti-thrombotiques $(97,7 \%$ par opposition à 99,8 \%; p = 0,08). Fait à souligner, un déclin dans l'abandon du tabagisme a été noté (35\% par opposition à $73 \% ; \mathrm{p}=0,02)$. Dans l'ensemble, les conditions d'une guérison optimale (optimal therapy status) ont été davantage atteintes dans la cohorte la plus récente comparativement à celle de 2008 à 2010 (52 \% par opposition à $22 \% ; \mathrm{p}<0,01$ ). Le fait d'être de sexe masculin a été associé à de meilleures conditions de guérison optimale (rapport des cotes: 1,61; IC $95 \%, 1,04-2,51)$. Enfin, mentionnons que le nombre de consultations de suivi et la durée des suivis n'ont pas été associés à l'atteinte de valeurs cibles en matière de prévention des AVC. Conclusions: Notre étude montre une série d'améliorations dans l'atteinte des objectifs thérapeutiques recommandés par les lignes directrices canadiennes de prévention des AVC. Cela pourrait être en partie

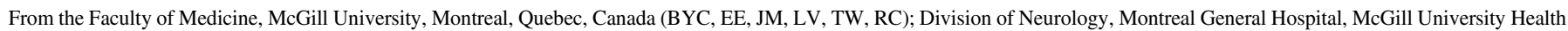

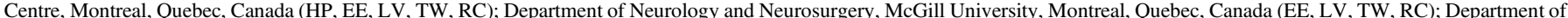
Neurosciences, Jewish General Hospital, Montreal, Quebec, Canada (JM); Division of Neurology, St. Marys Hospital, Montreal, Quebec, Canada (TW).

Received May 29, 2018. Final Revisions Submitted August 3, 2018. Date of Acceptance August 30, 2018.

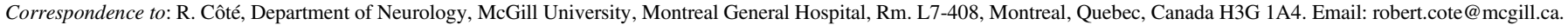


attribuable à la mise en place de dossiers médicaux informatisés au sein de notre clinique. Parmi les aspects qui méritent une amélioration, citons l'établissement d'un programme de counseling en ce qui regarde l'abandon du tabagisme et le dépistage du diabète.

Keywords: Stroke prevention, Vascular risk factor, Guideline, Electronic medical record doi:10.1017/cjn.2018.352

\section{INTRODUCTION}

Every year, 62,000 Canadians are diagnosed with a new stroke or transient ischemic attack (TIA), and 400,000 Canadians suffer from consequences of previous stroke. ${ }^{1}$ Stroke survivors face increased short- and long-term risk of recurrent stroke. ${ }^{2}$ Early initiation of secondary stroke prevention, by identifying and controlling modifiable risk factors and initiating medical or surgical interventions, has been associated with improved patient outcomes. ${ }^{3-7}$ Stroke prevention clinics (SPC) act as a form of organized secondary stroke prevention care, and early referral to SPC has been associated with reduced post-stroke mortality. ${ }^{3}$

We previously published our SPC's performance between 2008 and $2010^{8}$ with considerations to the practice guidelines from the Canadian Stroke Best Practice Recommendation at that time. ${ }^{9}$ Recent updates to these guidelines, ${ }^{10}$ especially in the areas of vascular imaging and detection of paroxysmal atrial fibrillation, have since then been incorporated into our clinical practice. In addition, we created standardized forms (initial evaluation and follow-up) integrated as electronic medical records for use in our SPC since 2014. One major potential benefit with the use of electronic medical records is that it may improve control of cardiovascular risk factors, likely by promoting better continuity of care between patient visits and thereby increasing adherence to guidelines. ${ }^{11}$ Therefore, our objective was to describe the level of adherence to recommended targets for control of stroke risk factors in our SPC over time, between 2008 and 2017.

\section{Material AND MethodS}

For purposes of comparison with our previously published results, ${ }^{8}$ a similar methodology was used, including patient inclusion and exclusion criteria, data collection, outcomes analysis, and data reporting.

\section{Study Design}

We hereby described a single-center retrospective cohort study, based at the Montreal General Hospital, a secondary stroke center within the McGill University Health Centre. This study was approved by the local research board of the McGill University Health Center Research Institute.

\section{Study Population}

We included all consecutive patients seen in the stroke prevention clinic for confirmed diagnosis of TIA or ischemic stroke between May 2014 and May 2017. Our clinic staff was composed of one RN, two administrative agents, and seven neurologists, and it has not changed over time. Patients were referred from one of three affiliated teaching hospitals (Montreal General Hospital, Royal Victoria Hospital, and Montreal Neurological Hospital) or from the community. Exclusion criteria included: patients with less than 6 months of follow-up (our previous report ${ }^{8}$ used 1 year as cut-off), hemorrhagic stroke, remote stroke or TIA (more than 6 months between ischemic event and initial clinic visit), stroke or TIA associated with non-atherosclerotic causes (cerebral venous thrombosis, arterial dissection, iatrogenic), stroke or TIA of both undetermined cause and without atherosclerotic vascular risk factors, and stroke or TIA occurring in patients of less than 45 years of age at the time of ischemic event. It is worth noting that the duration of follow-up and number of follow-up visits were not predetermined but based on completed investigations, patient needs, clinical condition, vascular neurologists' availabilities, and judgment.

\section{Electronic Medical Record}

Before 2014, all clinic visit notes were handwritten and subsequently scanned. Since then, we have implemented a new structured template for clinic visits, and we have advocated for its use by all neurologists at our SPC. This template contains typical sections for both initial visits and follow-up visits, including: basic visit identifiers, medical history and cardiovascular risk factors, social history, medications, basic stroke event identifiers, new vascular events (TIA, stroke, and myocardial infarction), current symptoms, physical exam including vital signs, summary of investigations, impression of stroke including etiology, and stroke management including control of risk factors. Once completed, this template could be saved as a clinic visit report within our institution's electronic medical record system and all recorded data could be exported to an electronic database for subsequent data analysis. It is important to note that our electronic medical record did not communicate with other healthcare institutions. Furthermore, the data included in the electronic medical record shared the same sources with the previous cohort, including information from family physicians when available. Both our templates for initial and follow-up visits are available as Supplementary data files.

\section{Measured Outcomes}

The main measured outcomes were derived from the Canadian guidelines for secondary stroke prevention, ${ }^{10}$ which include blood pressure-BP (target less than 140/90 for non-diabetic patients, and less than 130/80 for diabetic patients), low-density lipoprotein cholesterol-LDL-C (less than $2.0 \mathrm{mmol} / \mathrm{L}$ ), and appropriate use of antithrombotic therapy (either antiplatelet or anticoagulant according to clinical indication). For each of these three outcomes, target was considered as: completely attained (CA) if target was attained at the last visit, partially attained (PA) if target was attained at least once not attained (NA) if target has never been attained. Optimal therapy for each patient was considered as: CA if all three above targets were attained, PA if at least one target was attained at least once, and NA if none of the above targets had ever been attained. Glycemic control was not included as an outcome 
because there is no specific target that has been linked with stroke prevention.

Although not included in these three main outcomes, smoking status was also recorded at each visit. Other recorded data included: basic demographic information, cardiovascular risk factors, medication, stroke/TIA, stroke subtypes, ${ }^{12}$ investigations, followup in clinic, new vascular events, and carotid interventions. All data were obtained from the electronic hospital records and Quebec Health Record (the latter only communicated certain investigations such as labs between Quebec institutions, as well as medication profile between Quebec pharmacies).

Diagnosis of hypertension was based on previous history and use of antihypertensive medication. Diagnosis of dyslipidemia was based on previous history and use of lipid-lowering medication. Diagnosis of diabetes was based on previous history, use of medication, and screening at initial visit (fasting blood glucose $>$ $7.0 \mathrm{mmol} / \mathrm{L}$ or glycated hemoglobin A1c $>7.0 \%$ ).

\section{Statistical Analysis}

Categorical data (e.g., sex, hypertension, diabetes) were presented as frequencies and proportions of the whole or a subpopulation. Continuous data (e.g., age, BP, LDL-C) were summarized by means and standard deviations or medians and interquartile range (IQR). Comparison of baseline characteristics, investigations and drug therapy, and attainment of therapeutic targets between our previous results (2008-2010) and recent results (2014-2017) was completed by using a contingency table Chi-Square test (for categorical variables) or Wilcoxon rank-sum test (for continuous variables). All comparisons were carried out using a two-sided test at a significance level of 0.05 unless otherwise specified.

Logistic regression analysis was used to determine factors that influence the attainment of stroke prevention targets (BP target, LDL-C target, and optimal therapy). Our multivariate regression models were specified a priori, based on our previous study. ${ }^{8}$ Baseline characteristics included were patient sex, diabetes mellitus, hypertension, dyslipidemia, systolic BP, LDL-C, smoking, number of follow-up visits (1 vs. 2 or more), and the length of follow-up. Data were analyzed using SAS version 9.4 (SAS Institute Inc., Cary, NC).

\section{RESULTS}

We combined data from the 2008 to 2010 cohort of patients at our stroke prevention clinic, ${ }^{8}$ also known as "previous cohort," as well as data from the 2014 to 2017 cohort, also known as "most recent cohort," in all comparative data analyses.

\section{Study Population}

Between May 2014 and May 2017, 392 patients were included in total, compared to 408 patients between 2008 and 2010. In our cohort, 1036 new consecutive patients were initially screened. Of these, 644 patients were excluded for the following reasons: follow-up duration less than 6 months, 501 (78\%); hemorrhagic stroke, $51(8 \%)$; remote stroke or TIA, $16(2 \%)$; stroke or TIA associated with non-atherosclerotic causes, $30(5 \%)$; stroke or TIA of undetermined cause and without vascular risk factors, 16
(2\%); patients with less than 45 years old at the time of ischemic event, 30 (5\%). Among the 392 included patients, 142 (36\%) were referred for TIA and 250 (64\%) for an ischemic stroke.

\section{Demographic Information and Clinical Follow-up}

Table 1 illustrates detailed data for demographic information, co-morbidities, medication, stroke subtypes, investigations, follow-up duration, and occurrence of new vascular events.

Our previous cohort showed a mean age of $68 \pm 13$ years with $194(47.5 \%)$ female patients, while our most recent cohort had a mean age of $70 \pm 11$ years and $169(43.1 \%)$ female patients.

Vascular risk factor profiles were also similar between our previous and recent cohorts, with respectively $285(69.9 \%)$ and $272(69.4 \%)$ hypertensive patients, 97 (23.8\%) and $98(25.0 \%)$ patients with diabetes mellitus, $237(58.1 \%)$ and $243(62.0 \%)$ patients with dyslipidemia, $72(17.6 \%)$ and $76(19.4 \%)$ patients with coronary artery disease, $69(16.9 \%)$ and $37(9.4 \%)$ smokers $(p<0.01)$, and $85(20.8 \%)$ and $87(22.2 \%)$ patients with at least three modifiable vascular risk factors. It is worth noting that, of the 276 patients without previously documented diabetes, only 181 $(65.6 \%)$ received screening for diabetes with either fasting blood glucose or glycated hemoglobin A1c. In addition, 53 $(13.0 \%)$ patients in our previous cohort had documented atrial fibrillation, compared with $86(21.9 \%)$ in our most recent cohort $(p=0.01)$.

Both our 2008-2010 and 2014-2017 cohorts had similar TOAST classification ${ }^{12}$ profiles, with respectively $107(26.2 \%)$ and $103(26.3 \%)$ patients with a symptomatic large-vessel occlusion, $60(14.7 \%)$ and $75(19.1 \%)$ patients with a cardioembolic etiology, $133(32.6 \%)$ and $109(27.8 \%)$ with small-vessel disease and $108(26.5 \%)$ and $105(26.8 \%)$ patients with an undetermined cause for their ischemic event.

When considering diagnostic investigations, some differences were found between our previous and most recent cohorts, with respectively $400(98.0 \%)$ and $359(91.6 \%)$ of patients having had a computed tomography (CT) of the brain $(p<0.01), 51(12.5 \%)$ and $200(51.0 \%)$ patients having had a CT angiography (CTA) $(p<0.01), 167(40.9 \%)$ and $174(44.4 \%)$ patients having had MRI of the brain $(p=0.32), 74(18.1 \%)$ and $50(12.8 \%)$ patients having had magnetic resonance angiography (MRA) of the brain $(p=0.04), 370(90.7 \%)$ and $283(72.2 \%)$ patients having had duplex imaging of the cervical large vessels $(p<0.01), 323$ (79.2\%) and $293(74.7 \%)$ patients had either transthoracic or transesophageal echocardiography $(p=0.14)$, and $160(39.2 \%)$ and $210(53.6 \%)$ patients had a Holter monitor $(p<0.01)$. Within our most recent cohort, among those having had a Holter monitor, 39 (9.9\% of the total cohort) patients also had a prolonged loop recording.

The average duration of follow-up is similar between our previous and most recent cohorts, with respectively three visits per patients over 15.8 months and $2.3 \pm 0.5$ visits per patients over $15.3 \pm 8.1$ months.

During follow-up, 59 new vascular events occurred in the 2008-2010 cohort compared to 56 new vascular events in the 2014-2017 cohort. The difference in the proportions of patients with new vascular events documented on follow-up is not statistically significant, with $52(12.7 \%)$ patients in the previous group and $43(11.0 \%)$ patients in the most recent group $(p=0.44)$. 
Table 1: Demographic information and clinical follow-up

\begin{tabular}{|c|c|c|c|c|}
\hline \multicolumn{2}{|l|}{ Characteristics } & $2008-2010(N=408)^{9}$ & 2014-2017 $(N=392)$ & $p$-value \\
\hline \multicolumn{2}{|l|}{ Age-yr (SD) } & $68(13)$ & $70(11)$ & 0.05 \\
\hline \multicolumn{2}{|l|}{ Female sex-no. $(\%)$} & $194(47.5)$ & $169(43.1)$ & 0.21 \\
\hline \multicolumn{2}{|l|}{ Hypertension-no. (\%) } & $285(69.9)$ & $272(69.4)$ & 0.89 \\
\hline \multicolumn{2}{|l|}{ Diabetes—no. (\%) } & $97(23.8)$ & $98(25.0)$ & 0.70 \\
\hline \multicolumn{2}{|l|}{ Dyslipidemia—no. (\%) } & $237(58.1)$ & $243(62.0)$ & 0.39 \\
\hline \multicolumn{2}{|l|}{ Coronary artery disease-no. (\%) } & $72(17.6)$ & $76(19.4)$ & 0.57 \\
\hline \multicolumn{2}{|l|}{ Smoking_no. (\%) } & $69(16.9)$ & $37(9.4)$ & $<0.01$ \\
\hline \multicolumn{2}{|l|}{ Atrial fibrillation-no. (\%) } & $53(13.0)$ & $86(21.9)$ & 0.01 \\
\hline \multirow[t]{3}{*}{ No. modifiable risk factors-no. (\%) } & 0 & $58(14.2)$ & $56(14.3)$ & \multirow[t]{3}{*}{0.89} \\
\hline & $1-2$ & $265(65.0)$ & $249(63.5)$ & \\
\hline & 3 or more & $85(20.8)$ & $87(22.2)$ & \\
\hline \multirow[t]{4}{*}{ Stroke subtype-no. (\%) } & Large artery & $107(26.2)$ & $103(26.3)$ & \multirow[t]{4}{*}{0.28} \\
\hline & Cardioembolic & $60(14.7)$ & $75(19.1)$ & \\
\hline & Small artery & $133(32.6)$ & $109(27.8)$ & \\
\hline & Undetermined & $108(26.5)$ & $105(26.8)$ & \\
\hline \multirow[t]{7}{*}{ Investigations-no. (\%) } & CT brain & $400(98.0)$ & 359 (91.6) & $<0.01$ \\
\hline & CTA & $51(12.5)$ & $200(51.0)$ & $<0.01$ \\
\hline & MRI & $167(40.9)$ & $174(44.4)$ & 0.32 \\
\hline & MRA & $74(18.1)$ & $50(12.8)$ & 0.04 \\
\hline & Duplex & $370(90.7)$ & $283(72.2)$ & $<0.01$ \\
\hline & Echocardiogram & $323(79.2)$ & $293(74.7)$ & 0.14 \\
\hline & Holter (including loop recording) & $160(39.2)$ & $210(53.6)$ & $<0.01$ \\
\hline \multirow[t]{2}{*}{ Follow-up in clinic } & Duration—month (SD) & $15.8(-)$ & $15.3(8.1)$ & - \\
\hline & No. visits—mean (SD) & $3(-)$ & $2.3(0.5)$ & - \\
\hline New vascular events-no. & & 59 & 56 & - \\
\hline No. patients with new vascular events—no. (\%) & & $52(12.7)$ & $43(11.0)$ & 0.44 \\
\hline
\end{tabular}

$\mathrm{CT}=$ computed tomography; $\mathrm{CTA}=$ computed tomography angiography; $\mathrm{DM}=$ diabetes mellitus; $\mathrm{HTN}=$ hypertension; $\mathrm{MRA}=$ magnetic resonance angiography; MRI = magnetic resonance imaging; no. = number; $\mathrm{SD}=$ standard deviation; $\mathrm{yr}=$ year; $-=$ no data.

\section{Attainment of Stroke Prevention Targets}

Table 2 presents the detailed data on attainment of the main therapeutic targets.

At their last follow-up visit, our most recent cohort had better attainment of recommended BP targets compared to our previous cohort $(p<0.01)$, with respectively $314(83.1 \%)$ and $253(70.3 \%)$ patients, $37(9.8 \%)$ versus $28(7.8 \%)$ patients having PA their targets, and $27(7.1 \%)$ versus $79(21.9 \%)$ patients having NA their targets. For the most recent cohort, overall mean BP was $127 \pm 15$ / $74 \pm 9 \mathrm{mmHg}$, with $125 \pm 14 / 73 \pm 8 \mathrm{mmHg}$ for the CA subgroup, $138 \pm 15 / 75 \pm 10 \mathrm{mmHg}$ for the PA subgroup, and $146 \pm 12 /$ $79 \pm 10 \mathrm{mmHg}$ for the NA subgroup. Recommended LDL-C targets were more optimally attained in our most recent cohort compared to our previous cohort $(p<0.01)$, with respectively 190 $(66.2 \%)$ and $151(45.5 \%)$ patients having CA their targets, 27 $(9.4 \%)$ and $7(2.1 \%)$ patients having PA their targets, and 70 (24.4\%) and $174(52.4 \%)$ patients not having attained their targets. Within the most recent cohort, overall median LDL-C was 1.9 with IQR of $1.6 \mathrm{mmol} / \mathrm{L}$, median LDL-C for the CA subgroup was 1.7 with IQR of $1.4 \mathrm{mmol} / \mathrm{L}$, median LDL-C for the PA subgroup was 1.9 with IQR of $1.6 \mathrm{mmol} / \mathrm{L}$, and median LDL-C for the NA subgroup was 2.8 with IQR of $2.2 \mathrm{mmol} / \mathrm{L}$.

Both our previous and most recent cohorts had similar antithrombotic use $(p=0.08)$, with respectively $407(99.8 \%)$ and 383 $(97.7 \%)$ patients having CA their targets, $0(0.0 \%)$ and $3(0.8 \%)$ patients having PA their targets, and $1(0.2 \%)$ and $6(1.5 \%)$ patients not having attained their targets. Smoking cessation was better attained in our previous cohort than our most recent $(p<0.01)$, with respectively 50 (72.5\% of smokers) and 13 (35.1\% of smokers) successfully stopped smoking at the time of their last follow-up visit.

Overall, our most recent cohort was better at reaching optimal therapy compared to our previous cohort $(p<0.01)$, with respectively $146(52.1 \%)$ versus $89(21.8 \%)$ patients having CA their therapeutic targets, and 134 (47.9\%) versus 319 (78.2\%) having PA their targets.

Estimates of odds ratios (OR) for factors at initial visit that influences the attainment of stroke prevention targets (BP, LDL$\mathrm{C}$, and optimal therapy) are presented in Table 3. The presence of diabetes was associated with a decreased chance of attainment BP 
Table 2: Attainment of stroke prevention targets

\begin{tabular}{|c|c|c|c|c|c|c|c|}
\hline \multicolumn{4}{|c|}{ 2008-2010 $(N=408)$-no. $(\%)^{9}$} & \multicolumn{3}{|c|}{ 2014-2017 $(N=392)-$ no. $(\%)$} & \multirow[b]{2}{*}{$p$-value } \\
\hline Targets & CA & PA & NA & CA & $\mathbf{P A}$ & NA & \\
\hline $\mathrm{BP}$ & $253(70.3)$ & $28(7.8)$ & 79 (21.9) & $314(83.1)$ & $37(9.8)$ & $27(7.1)$ & $<0.01$ \\
\hline LDL-C & $151(45.5)$ & $7(2.1)$ & $174(52.4)$ & $190(66.2)$ & $27(9.4)$ & $70(24.4)$ & $<0.01$ \\
\hline Antithrombotic use & $407(99.8)$ & $0(0.0)$ & $1(0.2)$ & $383(97.7)$ & $3(0.8)$ & $6(1.5)$ & 0.08 \\
\hline Smoking cessation & $50(72.5)$ & $-(-)$ & $19(27.5)$ & $13(35.1)$ & $-(-)$ & $24(64.9)$ & $<0.01$ \\
\hline Optimal therapy & $89(21.8)$ & $319(78.2)$ & $0(0.0)$ & $146(52.1)$ & $134(47.9)$ & $0(0.0)$ & $<0.01$ \\
\hline
\end{tabular}

$\mathrm{BP}=$ blood pressure; $\mathrm{CA}=$ completely attained; LDL-C $=$ low-density lipoprotein cholesterol; $\mathrm{NA}=$ not attained; no. $=$ number; $\mathrm{PA}=$ partially attained; $-=$ no data.

Table 3: Multivariate analysis of factors associated with attainment of stroke prevention targets (BP, LDL-C, optimal therapy)

\begin{tabular}{l|l|l}
\hline Factor at initial visit & Target & OR (95\% CI) \\
\hline Diabetes & BP & $0.24(0.13-0.45)$ \\
\hline Diabetes & LDL-C & $2.03(1.23-3.34)$ \\
\hline Increased systolic BP (per mmHg) & BP & $0.96(0.94-0.98)$ \\
\hline Male sex & Optimal therapy & $1.61(1.04-2.51)$ \\
\hline Higher baseline LDL-C (per mmol/L) & Optimal therapy & $1.50(1.24-1.81)$ \\
\hline
\end{tabular}

$\mathrm{BP}=$ blood pressure; $\mathrm{CI}=$ confidence interval; LDL-C = low-density lipoprotein cholesterol; OR = odds ratios.

target with an OR (95\% confidence interval) of $0.24(0.13-0.45)$, but an increased chance of attainment of LDL-C target with an OR of 2.03 (1.23-3.34); increased systolic BP (per $\mathrm{mmHg}$ ) was associated with a decreased chance of attainment of BP target, with an OR of $0.96(0.94-0.98)$. Males were more likely to achieve the attainment of optimal therapy with an OR of 1.61 (1.04-2.51), while a higher baseline LDL-C (per mmol/L) was associated with an increased chance of attainment of optimal therapy with an OR of 1.50 (1.24-1.81). The number of follow-up visits and the length of follow-up, however, were not associated with the attainment of stroke prevention targets.

\section{DISCUSSION}

We previously published our experience pertaining to the performance of our stroke prevention clinic in managing vascular risk factors and reaching recommended therapeutic targets between 2008 and $2010{ }^{8}$ Since 2014, we have introduced standardized and structured electronic clinical forms to record relevant information during initial and follow-up clinic visits. Our current study not only shows that most patients at our clinic were adequately managed in regard to control of risk factors and antithrombotic therapy compared to other previously published studies $^{13-15}$ but also that our most recent cohort was generally more successful at attaining the main therapeutic targets for secondary stroke prevention compared to our previous cohort.

Overall, more than half $(52.1 \%)$ of the patients in our most recent cohort completely attained all of the three therapeutic targets (BP control, LDL-C $<2.0 \mathrm{mmol} / \mathrm{L}$ level, and adequate antithrombotic treatment) at their last follow-up visit, in comparison with $21.8 \%$ in our previous cohort $(p<0.01)$. Although both cohorts had similarly excellent adherence to antithrombotic therapy $(p=0.08)$, both BP control and LDL-C levels were significantly better in our most recent cohort $(p<0.01)$, this contributed to more patients attaining an optimal therapy status. The substantial improvement in these two therapeutic targets could be attributed to two factors. First and most importantly, recent years have seen an increased interest in secondary stroke prevention, the role of organizational restructuring in improving outcomes, and interventions to increase adherence to guidelines. ${ }^{16-19}$ This increased interest may have promoted the culture of stroke prevention within healthcare institutions. More specifically, in 2013, the Quebec health ministry established a 5-year action plan to improve the organization of stroke care in Quebec, which has led to the designation of several stroke centers in the province. In 2014, our institution successfully received accreditation as a secondary and tertiary stroke center. Second, the implementation of standardized templates through the use of electronic medical records may have been a factor associated with better adherence to guidelines in our most recent cohort, although this remains an unproven hypothesis. Studies have not conclusively shown a clear improvement in patient outcomes attributed directly to the use of electronic medical records, however, the latter could be beneficial by systematically prompting healthcare professionals to address key points during a patient encounter, especially if these points relate to recommended guidelines. ${ }^{1,20}$

Although we documented improvement in adherence to recommended targets, this did not translate into any significant reduction in the proportion of patients with new vascular events during the follow-up period $(p=0.44)$, despite similar mean follow-up lengths and generally similar demographic profiles. Our main objective was to assess the level of adherence to stroke prevention guidelines over time in a stroke prevention setting. Although the main purpose of a stroke prevention clinic is to 
reduce the number of vascular events, this was not the main objective of our study as we did not have complete access to follow-up clinical information if the patient did not continue to be followed in the clinic (lost to follow-up) or if an event occurred outside of our institution and was not reported to us, as our electronic medical records did not have the capability to link with other regional or provincial healthcare databanks. Therefore, our vascular event reporting provided only a partial picture of these clinical outcomes and represents a limitation of our study.

As for smoking cessation, our most recent cohort did worse than our previous cohort with respectively $35.1 \%$ compared to $72.5 \%$ of successful smoking cessation among initially active smokers at the last follow-up visit $(p<0.01)$. In addition, the proportion of initially active smokers was significantly lower in the most recent cohort compared to the previous cohort $(p<0.01)$. One plausible explanation for these discrepancies could be related to the different definitions of "active smoker." In the 2008-2010 cohort, previously active smokers who quit following their ischemic event and prior to their first clinic visit were considered to have successfully quit smoking. In the 2014-2017 cohort, patients who quit smoking prior to their first clinic visit were considered to be non-smokers, consequently reducing the overall number of smokers as well as the proportion of patients that quit smoking. Thus we cannot directly compare this variable between both cohorts and this represents another limitation of our approach.

Major updates in the Canadian stroke guidelines were introduced since 2010, addressing changes in recommended stroke investigations. ${ }^{21}$ These changes were reflected in the differences between our most recent cohort and previous cohort, such as increased use of CTA $(p<0.01)$, reduced use of MRA $(p=0.04)$, reduced use of duplex imaging of large vessels $(p<0.01)$, increased use of Holter monitor $(p<0.01)$, and the addition of loop recording (the latter two investigations leading to an increase in the detection of paroxysmal atrial fibrillation). Although CTA has a sensitivity of $96-100 \%,{ }^{22}$ slightly greater than carotid sonography at $90-98 \%,{ }^{23}$ the difference is not considerable enough to result in significant change in detecting large-vessel etiology between our two groups. On the contrary, for every eight patients with negative Holter, one patient has positive loop monitoring. ${ }^{24}$

However, one aspect that could be improved relates to the systematic diabetic screening for all patients at initial visit. Although it was recommended by Canadian guidelines, ${ }^{10}$ only $65.6 \%$ of all patients with previously unknown diabetic profile were screened in our study.

A few findings from our multivariate analysis of factors associated with attainment of stroke prevention targets are noteworthy. The presence of diabetes was associated with a poorer attainment of BP target. This parallels our previous findings and could be explained by a more strict BP target for the diabetic population. ${ }^{8}$ However, the presence of diabetes was associated with a better attainment of LDL-C target. Given that the literature has consistently demonstrated worse lipid profile in diabetic compared to non-diabetic patients, ${ }^{25,26}$ it may be possible that a more aggressive lipid management was employed among diabetic patients in our clinic. The same hypothesis could be applied to the correlation between worse lipid profile at initial visit and better optimal therapy at last visit. Furthermore, male sex was associated with better optimal therapy, which has been previously demonstrated in the literature and may be related to multifactorial causes including biological and social factors. ${ }^{27}$ Finally, although there were differences between our previous study and our current results regarding cut-off for follow-up duration, neither the length of follow-up nor the number of visits was associated with changes in attainment of therapeutic targets.

Strengths of our study include a relatively large sample of patients with combined data from two cohorts disseminated in time, length of follow-up, and excellent quality of prospectively recorded clinical information directly extracted from a comprehensive electronic database in the case of our most recent cohort. However, several limitations are noteworthy. First, given the nature of this single-center observational retrospective study, confounding biases could not be eliminated. Second, as previously mentioned, our patient population was non-captive, rendering accurate assessment of risk for recurrent ischemic events less reliable. Third, we, unfortunately, did not collect data regarding the specific type of recurrent vascular events, whether they were cerebrovascular or cardiovascular events. Fourth, given the lack of a contemporary control group, the positive impact of electronic medical records on attainment of therapeutic targets remains inconclusive, despite its theoretical benefits in improving adherence to guidelines.

We demonstrated an overall improvement in reaching recommended stroke prevention therapeutic targets ${ }^{10}$ in our most recent cohort, mainly attributed to a more positive stroke prevention culture over recent years and the systematic prompting benefit from our electronic medical record templates. These results further support the role of organized SPC in improving the quality of stroke care following a cerebral ischemic event.

\section{ACKNOWLEDGMENTS}

We would like to acknowledge Xun Zhang's contribution for statistical analysis (multivariate analysis).

\section{Data Statement}

Our data are available for review and shall be provided upon request.

\section{Disclosures}

Bing Yu Chen, Heather Perkins, Eric Ehrensperger, Jeffrey Minuk, Lucy Vieira, Theodore Wein, and Robert Côté have nothing to disclose.

\section{Statement of Authorship}

BYC collected and analyzed the data, and drafted the manuscript. HP collected the data. All authors provided input into data analysis and manuscript review.

\section{SupPlementary Material}

To view supplementary material for this article, please visit https://doi.org/10.1017/cjn.2018.352

\section{REFERENCES}

1. 2017 Stroke Report. Available at: http://www.strokebestpractices.ca/ wp-content/uploads/2017/06/HS_StrokeReport2017_EN.pdf. Accessed May 21, 2018.

2. Edwards JD, Kapral MK, Fang J, Swartz RH. Long-term morbidity and mortality in patients without early complications after stroke or transient ischemic attack. CMAJ. 2017;189(29):E954-61.

3. Webster F, Saposnik G, Kapral MK, Fang J, O'Callaghan C, Hachinski V. Organized outpatient care: stroke prevention clinic 
referrals are associated with reduced mortality after transient ischemic attack and ischemic stroke. Stroke. 2011;42(11):3176-82.

4. Rahiman A, Saver JL, Porter V, et al. In-hospital initiation of secondary prevention is associated with improved vascular outcomes at 3 months. J Stroke Cerebrovasc Dis. 2008;17(1):5-8.

5. Bruls S, Van Damme H, Defraigne JO. Timing of carotid endarterectomy: a comprehensive review. Acta Chir Belg. 2012;112(1):3-7.

6. Touze E, Coste J, Voicu M, et al. Importance of in-hospital initiation of therapies and therapeutic inertia in secondary stroke prevention: IMplementation of Prevention After a Cerebrovascular evenT (IMPACT) Study. Stroke. 2008;39(6):1834-43.

7. Ovbiagele B, Saver JL, Fredieu A, et al. In-hospital initiation of secondary stroke prevention therapies yields high rates of adherence at follow-up. Stroke. 2004;35(12):2879-83.

8. Al-Salti A, Vieira L, Cote R. Adherence to guidelines: experience of a Canadian stroke prevention clinic. Can J Neurol Sci. 2014;41 (5):562-67.

9. Lindsay P, Bayley M, McDonald A, Graham ID, Warner G, Phillips S. Toward a more effective approach to stroke: Canadian Best Practice Recommendations for Stroke Care. CMAJ. 2008;178 (11):1418-25.

10. Wein T, Lindsay MP, Cote R, et al. Canadian stroke best practice recommendations: secondary prevention of stroke, sixth edition practice guidelines, update 2017. Int J Stroke. 2018;13(4):420-43.

11. Roumia M, Steinhubl S. Improving cardiovascular outcomes using electronic health records. Curr Cardiol Rep. 2014;16(2):451.

12. Kolominsky-Rabas PL, Weber M, Gefeller O, Neundoerfer B, Heuschmann PU. Epidemiology of ischemic stroke subtypes according to TOAST criteria: incidence, recurrence, and longterm survival in ischemic stroke subtypes: a populationbased study. Stroke. 2001;32(12):2735-40

13. Saposnik G, Goodman SG, Leiter LA, et al. Applying the evidence: Do patients with stroke, coronary artery disease, or both achieve similar treatment goals? Stroke. 2009;40(4):1417-24.

14. Joseph LN, Babikian VL, Allen NC, Winter MR. Risk factor modification in stroke prevention: the experience of a stroke clinic. Stroke. 1999;30(1):16-20.

15. Rudd AG, Lowe D, Hoffman A, Irwin P, Pearson M. Secondary prevention for stroke in the United Kingdom: results from the National Sentinel Audit of Stroke. Age Ageing. 2004;33 (3):280-86.
16. Peng B, Ni J, Anderson CS, et al. Implementation of a structured guideline-based program for the secondary prevention of ischemic stroke in China. Stroke. 2014;45(2):515-9.

17. Lager KE, Mistri AK, Khunti K, Haunton VJ, Sett AK, Wilson AD. Interventions for improving modifiable risk factor control in the secondary prevention of stroke. Cochrane Database Syst Rev. 2014;(5):CD009103.

18. Vestergaard AS, Ehlers LH. A health economic evaluation of stroke prevention in atrial fibrillation: guideline adherence versus the observed treatment strategy prior to 2012 in Denmark. Pharmacoeconomics. 2015;33(9):967-79.

19. Lindsay MP, Kelloway L, Davies-Schinkel C, et al. Report: The Canadian Best Practices Educational Toolkits: translating evidence-based stroke recommendations into practical implementation resources. Can J Neurosci Nurs. 2011;33(3):11-2.

20. Boyle R, Solberg L, Fiore M. Use of electronic health records to support smoking cessation. Cochrane Database Syst Rev. 2014; (12):CD008743.

21. Casaubon LK, Boulanger JM, Glasser E, et al. Canadian Stroke Best Practice Recommendations: acute inpatient stroke care guidelines, update 2015. Int J Stroke. 2016;11(2):239-52.

22. Berg MH, Manninen HI, Rasanen HT, Vanninen RL, Jaakkola PA. CT angiography in the assessment of carotid artery atherosclerosis. Acta Radiol. 2002;43(2):116-24.

23. Jahromi AS, Cina CS, Liu Y, Clase CM. Sensitivity and specificity of color duplex ultrasound measurement in the estimation of internal carotid artery stenosis: a systematic review and meta-analysis. J Vasc Surg. 2005;41(6):962-72.

24. Galli A, Ambrosini F, Lombardi F. Holter monitoring and loop recorders: from research to clinical practice. Arrhythm Electrophysiol Rev. 2016;5(2):136-43.

25. Ali F, Jamil H, Anwar SS, Wajid N. Characterization of lipid parameters in diabetic and non-diabetic atherosclerotic patients. J Geriatr Cardiol. 2015;12(1):37-43.

26. Costa J, Borges M, David C, Vaz Carneiro A. Efficacy of lipid lowering drug treatment for diabetic and non-diabetic patients: meta-analysis of randomised controlled trials. BMJ. 2006;332 (7550):1115-24.

27. Zhao M, Vaartjes I, Graham I, et al. Sex differences in risk factor management of coronary heart disease across three regions. Heart. 2017;103(20):1587-94. 